\title{
Walled-off peripancreatic fluid collections in Asian population: Paradigm shift from surgical and percutaneous to endoscopic drainage
}

\author{
Nonthikorn Theerasuwipakorn*1, Abbas Ali Tasneem ${ }^{* 2,3}$, Pradermchai \\ Kongkam $^{1,2,4}$, Phontep Angsuwatcharakon ${ }^{1,2}$, Wiriyaporn Ridtitid ${ }^{1,2}$, Patpong \\ Navicharern $^{1}$, Krit Kitisin ${ }^{1}$, Peerapol Wangrattanapranee ${ }^{2}$, Rungsun Rerknimitr ${ }^{1,2}$, \\ Pinit Kullavanijaya ${ }^{1,2}$ \\ 'Faculty of Medicine, Chulalongkorn University and King Chulalongkorn Memorial Hospital, \\ Thai Red Cross Faculty of Medicine, Chulalongkorn University Society, Bangkok, Thailand; \\ ${ }^{2}$ Gastrointestinal Endoscopy Excellence Center, King Chulalongkorn Memorial Hospital, \\ Thai Red Cross Society, Bangkok, Thailand; \\ ${ }^{3}$ Department of Hepatogastroenterology, Sindh Institute of Urology and Transplantation, Karachi, Pakistan; \\ ${ }^{4}$ Pancreas Research Unit, Department of Medicine, Faculty of Medicine, \\ Chulalongkorn University, Bangkok, Thailand
}

*These authors contributed equally and are co-first authors.

Address for Correspondence: Dr. Pradermchai Kongkam,

Gastrointestinal Endoscopy Excellence Center, King Chulalongkorn Memorial Hospital, Thai Red Cross Society, Bangkok, Thailand.

E-mail: Kongkam@hotmail.com

\begin{tabular}{|l|}
\hline Access this article online \\
\hline $\begin{array}{l}\text { Website: } \\
\text { www.intern-med.com }\end{array}$ \\
\hline $\begin{array}{l}\text { DOI: } \\
\text { 10.2478/jim-2019-0032 }\end{array}$ \\
\hline Quick Response Code: \\
\hline \\
\\
\\
\\
\end{tabular}

\section{ABSTRACT}

Background and Objectives: Drainage of symptomatic walled-off peripancreatic fluid collections (WPFCs) can be achieved by endoscopic, percutaneous, and surgical techniques. The aim of this study was to determine the current trends in management of WPFCs and the outcome of such modalities in Asian population. Methods: In this retrospective analysis, all patients diagnosed with pancreatitis from 2013 to 2016 in King Chulalongkorn Memorial Hospital, Bangkok, Thailand, were analyzed. Relevant clinical data of all patients with peripancreatic fluid collections (PFCs) was reviewed. Clinical success was defined as improvement in symptoms after drainage. Results: Of the total 636 patients with pancreatitis, $72(11.3 \%)$ had WPFCs, of which $55(8.6 \%)$ and $17(2.7 \%)$ had pancreatic pseudocyst (PP) and walled-off necrosis (WON), respectively. The commonest etiologies of WPFCs were alcohol (38.9\%) and biliary stone $(29.2 \%)$. Post-procedure and pancreatic tumor related pancreatitis was found in $8.3 \%$ and $6.9 \%$ patients, respectively. PP was more common in chronic $(27.8 \%)$ than acute $(5.5 \%)$ pancreatitis. Of the 72 patients with WPFCs, 31 (43.1\%) had local complications. Supportive, endoscopic, percutaneous, and surgical drainage were employed in $58.3 \%, 27.8 \%, 8.3 \%$, and $5.6 \%$ with success rates being $100 \%, 100 \%, 50 \%$, and $100 \%$, respectively. Complications that developed after percutaneous drainage included bleeding at procedure site $(n=1)$, infection of PFC $(n=1)$, and pancreatic duct leakage $(n=1)$. Conclusion: Over the past few years, endoscopic drainage has become the most common route of drainage of WPFCs followed by percutaneous and surgical routes. The success rate of endoscopic route is better than percutaneous and comparable to surgical modality.

Key words: peripancreatic fluid collection, pancreatic necrosis, pseudocyst, pancreatitis, EUS-guided pseudocyst drainage, pancreatic necrosectomy, endoscopic ultrasound, endoscopic retrograde cholangiopancreatography, walled-off necrosis, pseudocyst drainage, natural history

\section{INTRODUCTION}

Both acute and chronic pancreatitis can lead to disruption of pancreatic duct and leakage of pancreatic enzymes that can auto-digest the surrounding tissues, resulting in the development of inflammatory fluid or necrotic tissue. Various local complications of pancreatitis from leakage of pancreatic juice are recently reclassified. Generally, after the onset of pancreatitis, for at least 4 weeks, the connective tissues may surround the inflammatory contents and form pancreatic pseudocyst or walledoff necrosis (WON). ${ }^{[1]}$ The incidence of pseudocyst following pancreatitis ranges from $1.0 \%$ to $6.3 \%$; however, some studies reported the incidence to be as high as 
Kongkam et al: : Walled-off peripancreatic fluid collections in Asian population

$14.6 \% .^{[2-4]}$ Pseudocysts develop more commonly after chronic than acute pancreatitis, while WON develops more commonly after acute than chronic pancreatitis. The most common causes of pancreatitis causing pseudocyst and WON are alcohol, biliary tract stone, trauma, and postendoscopic procedures, in order of frequencies. ${ }^{[5-6]}$

Patients with pseudocyst and WON commonly present with abdominal pain, anorexia, nausea, vomiting, fever, weight loss, or may be found incidentally by imaging performed in otherwise asymptomatic patients. The examination findings may include abdominal tenderness, palpable mass, and abdominal fluid collection. ${ }^{[5]}$ There are various therapeutic strategies that can be employed in patients with pseudocyst and WON. In patients with mild symptoms, conservative management can be employed with good clinical outcome. ${ }^{[7]}$ On the other hand, patients with severe symptoms resulting from pseudocyst and WON including infection and gastric outlet obstruction may require additional therapeutic intervention to drain these walled-off peripancreatic fluid collections (WPFCs). The three main drainage techniques used for pseudocyst or WON are endoscopic, percutaneous, and surgical drainage. ${ }^{[8-12]}$

Although most of the current studies concerning the management of pseudocyst and WON focus on newer therapeutic techniques especially endoscopic drainage, there are only few studies comparing these three therapeutic drainage methods in daily practice. The aim of this study, therefore, was to report the natural history of pancreatitis and current trends of management techniques for WPFC and the outcomes of such therapeutic modalities in a large referral hospital.

\section{METHODS}

We searched patients presenting to King Chulalongkorn Memorial Hospital (KCMH) from 2013 to 2016 who had pancreatic pseudocyst (ICD-10 K863) or WON associated with acute (ICD-10 K85) or chronic pancreatitis (ICD-10 K860) by retrospectively reviewing the OPD card, IPD record, or abdominal imaging. We then collected and analyzed the data to study the natural history, indications of the procedures, management techniques employed, associated complications, and outcomes of the treatment. All patients with ages greater than 15 years and having pseudocyst or WON from acute or chronic pancreatitis were included. Patients with an inadequate medical record or those with end-stage disease were excluded from the study. The steps involved in drainage of WPFC included identification of the gastric or duodenal mucosal bulge, puncturing of this site with needle knife papillotome, insertion of guidewire into the fluid collection under fluoroscopic guidance, dilatation of the tract with Soehendra biliary dilator, and finally placement of a double pigtail plastic stent (Video 1). Treatment was regarded as clinically successful if the drainage procedure was successfully performed without changing the primary drainage procedure to other method, and the patient had none of the previously existing symptoms or had minimal symptoms that could be treated conservatively. Similarly, treatment was regarded as a failure if the patient required different mode of drainage or was unresponsive to the treatment with persistence of pre-treatment symptoms or had developed complications. The protocol of the study was approved by the ethical committee of the hospital.

We used Statistical Package for the Social Sciences (SPSS) software (version 20) to analyze the data. Continuous data was represented by medians with interquartile ranges, while categorical data was represented by numbers and percentages.

\section{RESULTS}

Of the 636 patients presenting with pancreatitis to $\mathrm{KCMH}$ between 2013 and 2016, $546(85.8 \%)$ had acute pancreatitis and $90(14.2 \%)$ had chronic pancreatitis. Among these, 72 patients had WPFCs with pancreatic pseudocysts in 55 and WON in 17 patients. Pseudocysts developed in $5.5 \%(30 / 546)$ and $27.8 \%(25 / 90)$ in patients with acute and chronic pancreatitis, respectively. WON developed in $2.6 \%(14 / 546)$ and $3.3 \%(3 / 90)$ in patients with acute and chronic pancreatitis, respectively (Figure 1).

The median age of the patients was 53 years (range 15-88 years; interquartile range (IQR) 43-64 years). There were 53 males with a male-to-female ratio of $2.8: 1$. The most common comorbid diseases were hypertension (29.2\%), diabetes mellitus $(25.0 \%)$, dyslipidemia $(20.8 \%)$, coronary artery disease $(5.5 \%)$, chronic kidney disease (4.2\%), chronic hepatitis B infection (4.2\%), benign prostatic hypertrophy (4.2\%), and other diseases (29.2\%) (Table 1$)$.

The causes of pancreatitis resulting in WPFCs were alcohol $(38.9 \%)$, stone $(29.2 \%)$, idiopathic $(12.5 \%)$, post procedure $(8.3 \%)$, and tumor (6.9\%), while drug (Lamivudine), trauma, and autoimmune (IgG4-related pancreatitis) were 1.4\% each (Table 1). The different types of tumors noted were pancreatic adenocarcinoma, pancreatic neuroendocrine tumor, intraductal papillary mucinous neoplasm, lung cancer metastasized to head of pancreas, and intraductal papillary neoplasm of the left lobe of liver (Table 1).

Among the 72 patients with WPFCs, 26 (36.0\%) had no symptoms. Among the symptomatic patients, the commonest complaints were abdominal pain $(55.6 \%)$ and 


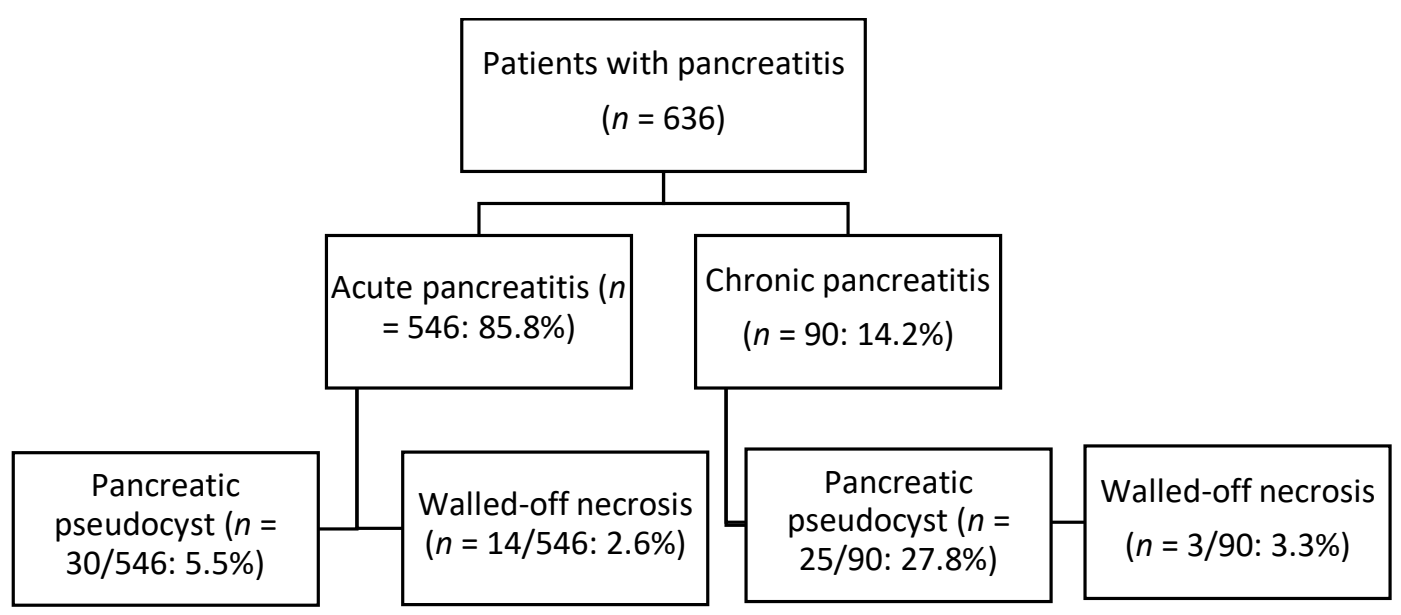

Figure 1: Number of patients with pancreatic pseudocyst and walled-off necrosis from acute and chronic pancreatitis from 2013 to 2016 at King Chulalongkorn Memorial Hospital (KCMH), Bangkok, Thailand.

\begin{tabular}{|c|c|c|c|}
\hline Parameters & $\begin{array}{l}\text { Pseudocyst } \\
(n=55)\end{array}$ & $\begin{array}{l}\text { Walled-off necrosis } \\
(n=17)\end{array}$ & $\begin{array}{l}\text { Total } \\
(n=72)\end{array}$ \\
\hline Male $-n(\%)$ & $40(72.7)$ & $13(76.5)$ & $53(73.6)$ \\
\hline \multicolumn{4}{|l|}{ Age (years) } \\
\hline - Median (IQR) & $50(42-65)$ & $58(46.5-65)$ & $53(43-64)$ \\
\hline - Range & $15-88$ & $31-73$ & $15-88$ \\
\hline \multicolumn{4}{|l|}{ Underlying diseases $-n(\%)$} \\
\hline - Hypertension & $13(23.6)$ & $8(47.0)$ & $21(29.2)$ \\
\hline - Diabetes mellitus & $15(27.3)$ & $3(17.6)$ & $18(25.0)$ \\
\hline - Dyslipidemia & $12(21.8)$ & $3(17.6)$ & $15(20.8)$ \\
\hline - Coronary artery disease & $3(5.5)$ & $1(5.9)$ & $4(5.5)$ \\
\hline - Chronic kidney disease & $2(3.6)$ & $1(5.9)$ & $3(4.2)$ \\
\hline - Chronic HBV infection & $3(5.5)$ & 0 & $3(4.2)$ \\
\hline - Benign prostatic hypertrophy & $3(5.5)$ & 0 & $3(4.2)$ \\
\hline - Others & $17(30.9)$ & $4(23.5)$ & $21(29.2)$ \\
\hline \multicolumn{4}{|l|}{ Etiologies of pancreatitis $-n(\%)$} \\
\hline - Alcohol & $22(40.0)$ & $6(35.3)$ & $28(38.9)$ \\
\hline - Stone & $13(23.6)$ & $8(47.0)$ & $21(29.2)$ \\
\hline - Idiopathic & $7(12.7)$ & $2(11.7)$ & $9(12.5)$ \\
\hline - Post procedure & $5(9.1)$ & $1(5.9)$ & $6(8.3)$ \\
\hline - Tumor & $5(9.1)$ & 0 & $5(6.9)$ \\
\hline - Drug & $1(1.8)$ & 0 & $1(1.4)$ \\
\hline - Trauma & $1(1.8)$ & 0 & $1(1.4)$ \\
\hline - IgG4-related pancreatitis & $1(1.8)$ & 0 & $1(1.4)$ \\
\hline
\end{tabular}

fever $(22.2 \%)$, followed by nausea or vomiting $(18.1 \%)$, anorexia and weight loss $(16.7 \%)$, jaundice $(12.5 \%)$, abdominal swelling (6.9\%), and dyspnea (2.8\%) (Table 2). The commonest signs were abdominal tenderness $(55.6 \%)$, palpable mass $(25.0 \%)$, raised body temperature $(20.8 \%)$, jaundice $(13.9 \%)$, pleural effusion $(5.6 \%)$, and ascites $(4.2 \%)$ (Table 2$)$.

The WPFCs were mostly single (50.0\%). However, two, three, or more were present in $20.8 \%, 11.1 \%$, and $18.1 \%$, respectively. The collections could be found arising from different regions of pancreas including body (59.7\%), tail $(40.3 \%)$, head $(34.7 \%)$, neck $(19.4 \%)$, and uncinate process $(18.1 \%)$. Mean size of the lesions was $7.9 \mathrm{~cm}(\mathrm{SD}, 5.7 \mathrm{~cm})$ and a range of $0.3-24 \mathrm{~cm}$ (Table 3).

Thirty-one patients had local complications from WPFCs. The complications were local infection $(26.4 \%)$, biliary tract obstruction (13.9\%), bowel obstruction (4.2\%), localized bleeding $(4.2 \%)$, pancreatico-pleural fistula $(2.8 \%)$, abdominal compartment syndrome $(1.4 \%)$, and portal vein stenosis $(1.4 \%)$ (Table 3 ). 
Kongkam et al.: Walled-off peripancreatic fluid collections in Asian population

\begin{tabular}{|c|c|c|c|}
\hline & $\begin{array}{l}\text { Pseudocyst } \\
(n=55)\end{array}$ & $\begin{array}{l}\text { Walled-off necrosis } \\
(n=17)\end{array}$ & $\begin{array}{l}\text { Total } \\
(n=72)\end{array}$ \\
\hline \multicolumn{4}{|l|}{ Symptom - $n(\%)$} \\
\hline - Asymptomatic & $22(40.0)$ & $4(23.5)$ & $26(36.1)$ \\
\hline - Abdominal pain & $28(50.9)$ & $12(70.6)$ & $40(55.6)$ \\
\hline - Fever & $9(16.4)$ & $7(41.2)$ & $16(22.2)$ \\
\hline - Nausea/vomiting & $9(16.4)$ & $4(23.5)$ & $13(18.1)$ \\
\hline - Anorexia & $10(18.2)$ & $2(11.7)$ & $12(16.7)$ \\
\hline - Weight loss & $11(20.0)$ & $1(5.9)$ & $12(16.7)$ \\
\hline - Jaundice & $8(14.5)$ & $1(5.9)$ & $9(12.5)$ \\
\hline - Palpable mass & $4(7.3)$ & $1(5.9)$ & $5(6.9)$ \\
\hline - Dyspnea & $2(3.6)$ & 0 & $2(2.8)$ \\
\hline \multicolumn{4}{|l|}{ Sign $-n(\%)$} \\
\hline - No abnormal sign & $22(40.0)$ & $3(17.6)$ & $25(34.7)$ \\
\hline - Abdominal tenderness & $28(50.9)$ & $12(70.6)$ & $40(55.6)$ \\
\hline - Palpable mass & $12(21.8)$ & $6(35.3)$ & $18(25.0)$ \\
\hline - Fever & $9(16.4)$ & $6(35.3)$ & $15(20.8)$ \\
\hline - Jaundice & $8(14.5)$ & $2(11.7)$ & $10(13.9)$ \\
\hline - Pleural effusion & $2(3.6)$ & $2(11.7)$ & $4(5.6)$ \\
\hline - Ascites & $3(5.5)$ & 0 & $3(4.2)$ \\
\hline
\end{tabular}

Table 3: Number, location, diameter, and local complications of pancreatic fluid collections were compared among pseudocyst, walled-off necrosis, and all patients.

\begin{tabular}{|c|c|c|c|}
\hline & $\begin{array}{l}\text { Pseudocyst } \\
(n=55)\end{array}$ & $\begin{array}{l}\text { Walled-off necrosis } \\
(n=17)\end{array}$ & $\begin{array}{l}\text { Total } \\
(n=72)\end{array}$ \\
\hline \multicolumn{4}{|l|}{ Number $-n(\%)$} \\
\hline - 1 lesion & $27(49.1)$ & 9 (52.9) & $36(50.0)$ \\
\hline - 2 lesions & $11(20.0)$ & $4(23.5)$ & $15(20.8)$ \\
\hline - 3 lesions & $6(10.9)$ & $2(11.7)$ & $8(11.1)$ \\
\hline$->3$ lesions & $11(20.0)$ & $2(11.7)$ & $13(18.1)$ \\
\hline \multicolumn{4}{|l|}{ Location $-n(\%)$} \\
\hline - Uncinate process & $8(14.5)$ & $5(29.4)$ & $13(18.1)$ \\
\hline - Head of pancreas & $18(32.7)$ & $7(41.2)$ & $25(34.7)$ \\
\hline - Neck of pancreas & $9(16.4)$ & $5(29.4)$ & $14(19.4)$ \\
\hline - Body of pancreas & $31(56.4)$ & $12(70.6)$ & $43(59.7)$ \\
\hline - Tail of pancreas & $20(36.4)$ & $9(52.9)$ & $29(40.3)$ \\
\hline \multicolumn{4}{|l|}{ Size } \\
\hline - Mean $(\mathrm{cm})$ (range) & $6.9(0.3-24.0)$ & $10.3(3.4-23.9)$ & $7.9(0.3-24.0)$ \\
\hline \multicolumn{4}{|l|}{ Complication $-n(\%)$} \\
\hline - Local infection & $12(21.8)$ & $7(41.2)$ & $19(26.4)$ \\
\hline - Biliary tract obstruction & $9(16.4)$ & $1(5.9)$ & $10(13.9)$ \\
\hline - Gut obstruction & $3(5.5)$ & $1(5.9)$ & $3(4.2)$ \\
\hline - Local bleeding & $3(5.5)$ & 0 & $3(4.2)$ \\
\hline - Pancreaticopleural fistula & $2(3.6)$ & 0 & $2(2.8)$ \\
\hline - Abdominal compartment syndrome & 0 & $1(5.9)$ & $1(1.4)$ \\
\hline - Portal vein stenosis & $1(1.8)$ & 0 & $1(1.4)$ \\
\hline
\end{tabular}

Among the 30 patients requiring drainage procedures, endoscopic drainage was performed in 20/72 (27.8\%) patients; percutaneous method was performed in 6/72 (8.3\%) patients; and surgical method was performed in 4/72 (5.6\%) patients. Fifteen $(15 / 72 ; 20.8 \%)$ patients with mild symptoms or complications were treated conservatively while the other $27(37.5 \%)$ who were incidentally found to have the lesion required no intervention (Figure 2, Tables 4 and 5).
Baseline characteristics of each therapeutic modality were compared. Among patients who underwent surgical drainage, none developed acute pancreatitis, whereas majority of patients who underwent the other two treatment modalities had acute pancreatitis. Half and all of the patients who underwent endoscopic and surgical drainage, respectively, had a single lesion, whereas half of the patients who underwent percutaneous drainage had more than three lesions (Table 6). 
The clinical success rates of the endoscopic, percutaneous, and surgical methods were $100 \%, 50 \%$, and $100 \%$ respectively (Figure 2). Complications developed only with the percutaneous modality including bleeding at procedural site $(n=1)$ that needed surgical correction, drain infection $(n=1)$ that was treated with antibiotics and revised percutaneous drain placement, and pancreatic duct leakage $(n=1)$ that was corrected with endoscopic retrograde cholangiopancreatography (ERCP) and pancreatic duct stent insertion.

\section{DISCUSSION}

Local complications of pancreatitis were recently classified based on the revised Atlanta classification of pancreatitis. ${ }^{[1]}$ Drainage of walled-off symptomatic PFC including pseudocyst and $\mathrm{WON}$ can be performed by endoscopic drainage, surgery, or percutaneous method. ${ }^{[13]}$ In this study, management and drainage methods of pseudocyst and WON were extensively reviewed. Regarding epidemiology, pseudocyst was found frequently in both acute and chronic pancreatitis; however, pseudocyst was more common in chronic than in acute pancreatitis (27.8\% and $5.5 \%$, respectively). This result is similar to those reported by several previous studies, which describe that a frequency of pseudocyst after acute pancreatitis was lower than that of chronic pancreatitis: $5-18.5 \% 0^{[3,14-16]}$ and $20-40 \%,{ }^{[17]}$ respectively. In this study, the frequency of WON was slightly lower than that reported by several previous reports $(4-16 \%){ }^{[18]}$ This may be attributed to the improvements in the management of pancreatitis in modern times.

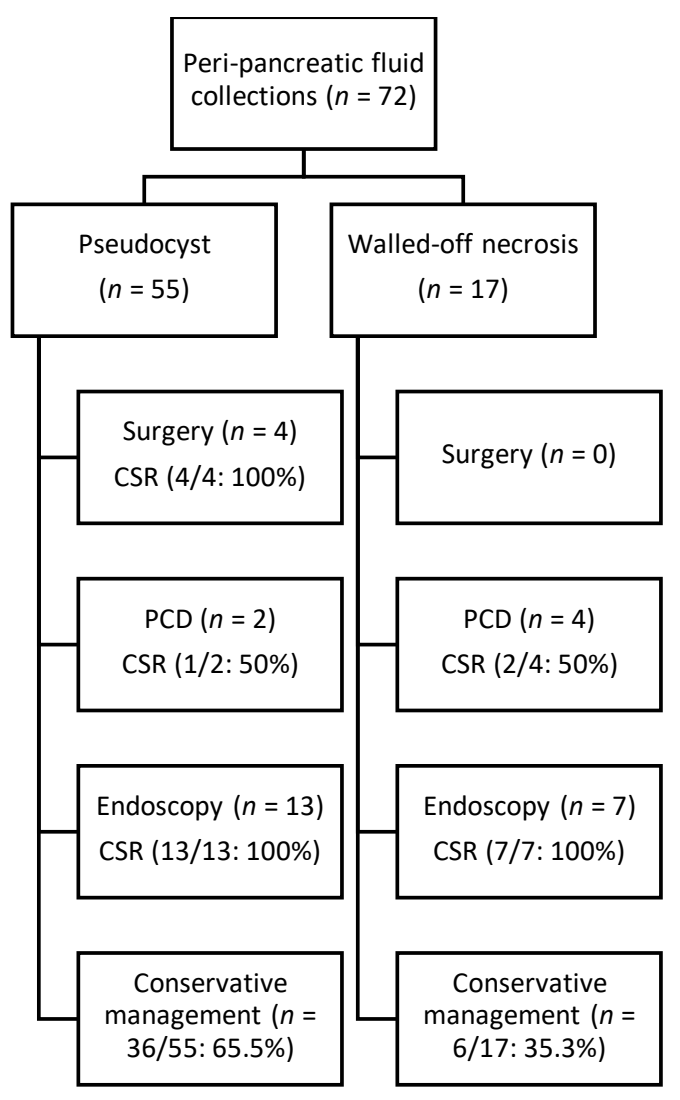

Figure 2: Management of patients with pancreatic fluid collections (PFCs) $(n=72)$. Indications for drainage of pseudocyst $(n=19)$ were infection $(n=8)$, abdominal pain $(n=4)$, biliary tract obstruction $(n=5)$, gut obstruction $(n=2)$, and bleeding $(n=2)$. Indications for drainage of walled-off necrosis (WON) $(n=11)$ were infection $(n=6)$, abdominal pain $(n=4)$, biliary obstruction $(n=1)$, and abdominal compartment syndrome $(n=1)$. CSR: clinical success rate; PCD: percutaneous drainage

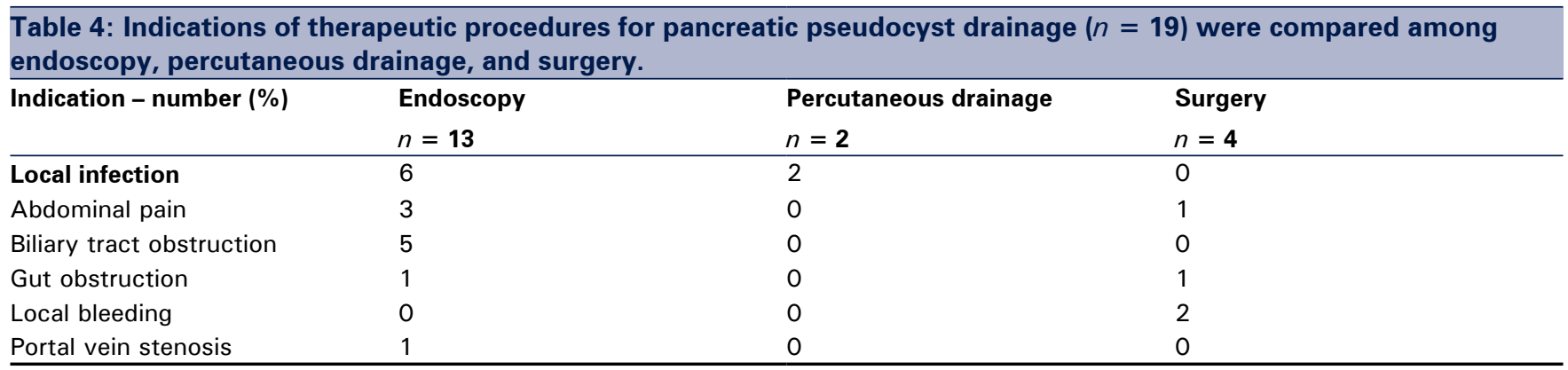

\begin{tabular}{|c|c|c|c|}
\hline \multicolumn{4}{|l|}{ Walled-off necrosis } \\
\hline Indication - number (\%) & $\begin{array}{l}\text { Endoscopy } \\
n=7\end{array}$ & $\begin{array}{l}\text { Percutaneous drainage } \\
n=4\end{array}$ & $\begin{array}{l}\text { Surgery } \\
n=0\end{array}$ \\
\hline Local infection & 5 & 1 & 0 \\
\hline Abdominal pain & 2 & 2 & 0 \\
\hline Biliary tract obstruction & 1 & 0 & 0 \\
\hline $\begin{array}{l}\text { Abdominal compartment } \\
\text { syndrome }\end{array}$ & 0 & 1 & 0 \\
\hline
\end{tabular}




\begin{tabular}{|c|c|c|c|}
\hline Baseline Characteristics & $\begin{array}{l}\text { Endoscopy } \\
(n=20)\end{array}$ & $\begin{array}{l}\text { Percutaneous drainage } \\
(n=6)\end{array}$ & $\begin{array}{l}\text { Surgery } \\
(n=4)\end{array}$ \\
\hline \multicolumn{4}{|l|}{ Age (years) } \\
\hline - Median (IOR) & $51(46.2-61.7)$ & $54(45.7-63.5)$ & $42.5(41.2-44.5)$ \\
\hline - Range & $15-73$ & $42-71$ & $41-45$ \\
\hline Male $-n(\%)$ & $14(70)$ & $6(100)$ & $3(75)$ \\
\hline Pancreatic pseudocyst $-n(\%)$ & $13(65)$ & $2(33.3)$ & $4(100)$ \\
\hline Type, acute $-n(\%)$ & $13(65)$ & $6(100)$ & 0 \\
\hline \multicolumn{4}{|l|}{ Cause of pancreatitis $-n(\%)$} \\
\hline - Alcohol & $6(30)$ & $4(66.7)$ & $3(75)$ \\
\hline - Stone & $7(35)$ & $1(16.7)$ & $1(25)$ \\
\hline - Idiopathic & $3(15)$ & 0 & 0 \\
\hline - Post procedure & $1(5)$ & $1(16.7)$ & 0 \\
\hline - Tumor & $2(10)$ & 0 & 0 \\
\hline - Trauma & $1(5)$ & 0 & 0 \\
\hline \multicolumn{4}{|l|}{ Number - $n(\%)$} \\
\hline - 1 lesion & $10(50)$ & $1(16.7)$ & $4(100)$ \\
\hline - 2 lesions & $6(30)$ & $1(16.7)$ & 0 \\
\hline - 3 lesions & $2(10)$ & $1(16.7)$ & 0 \\
\hline$->3$ lesions & $2(10)$ & $3(50)$ & 0 \\
\hline \multicolumn{4}{|l|}{ Location - $n(\%)$} \\
\hline - Uncinate process & $2(10)$ & $1(16.7)$ & $1(25)$ \\
\hline - Head of pancreas & $5(25)$ & $3(50)$ & $1(25)$ \\
\hline - Neck of pancreas & $3(15)$ & $2(33.3)$ & $1(25)$ \\
\hline - Body of pancreas & $13(65)$ & $6(100)$ & $1(25)$ \\
\hline - Tail of pancreas & $13(65)$ & $3(50)$ & $1(25)$ \\
\hline \multicolumn{4}{|l|}{ Size } \\
\hline - Mean (cm) & 11.8 & 12.6 & 7.8 \\
\hline - Standard deviation (SD) & 5.1 & 6.9 & 2.7 \\
\hline - Range (cm) & $4.2-23.9$ & $4.0-24.0$ & $5.4-11.5$ \\
\hline \multicolumn{4}{|l|}{ Indication - $n(\%)$} \\
\hline - Local infection & $11(55)$ & $3(50)$ & 0 \\
\hline - Abdominal pain & $5(25)$ & $2(33.3)$ & $1(25)$ \\
\hline - Biliary tract obstruction & $6(30)$ & 0 & $1(25)$ \\
\hline - Gut obstruction & $1(5)$ & 0 & $1(25)$ \\
\hline
\end{tabular}

Alcohol was the most common cause of pancreatitis resulting in pseudocyst and WON (38.9\%) followed by biliary stone $(29.2 \%)$ and idiopathic $(12.5 \%)$. These results are comparable to previous studies that reported the frequencies to be $52-72 \%$ from alcohol, $8-31 \%$ from biliary stone, and $10-16 \%$ from idiopathic cause. ${ }^{[3,5,6]}$ However, a more detailed analysis shows that, although alcohol is still the most common cause, its proportion has decreased. The reason is probably the significant rise in the number of post-procedural pancreatitis $(8.3 \%$ versus $0.3-$ $1 \%){ }^{[5,6]}$ The number of endoscopic procedures performed has increased over the last few years, thereby increasing the number of complications associated with them including PFCs. Another explanation is the rise in the pancreatic tumor-related pancreatitis $(6.9 \%)$ and its complications that previously remained relatively underreported. ${ }^{[19]}$
In this study, the commonest symptoms associated with pseudocyst were abdominal pain, anorexia, weight loss, nausea, vomiting, and fever. However, $40 \%$ of the patients with pseudocyst had no symptoms at all. The symptoms of patients with WON were similar to those of patients with pseudocyst, except that lesser number of patients with WON was asymptomatic (23.5\%). Interestingly, among the patients who were asymptomatic, the patients with pseudocyst were twice as many as those with WON, indicating that the latter had a relatively more severe clinical course. This finding is in contrast to that of other studies performed in the past, which show varying number of asymptomatic patients depending on the population included in each study. ${ }^{[3,6,20]}$ Also, patients with WON developed greater number of complications and required more frequent therapeutic interventions than those with 
pseudocyst (64.7\% versus $34.5 \%$ ). However, the types of complications were the same in both groups, including local infection, abdominal pain, biliary tract obstruction, bowel obstruction, and local bleeding.

The various therapeutic modalities employed in this study were supportive, endoscopic, percutaneous, and surgical drainage, with their respective frequencies being $58.3 \%$ (42/72), $27.8 \%$ (20/72), $8.3 \%(6 / 72)$, and $5.6 \%(4 / 72)$ and their respective success rates being $100 \%, 100 \%$, $50 \%$, and $100 \%$. Percutaneous drainage that had the lowest success rate was performed more in patients with acute pancreatitis $(100 \%)$, WON (66.7\%), and multiple lesions $(50 \%)$. Therefore, lower clinical success rate of percutaneous drainage can be simply explained by more complex clinical scenario of patients in this group. The success rates of these procedures that have been reported in the studies published in the past two decades range from $80 \%$ to $100 \%$, which is similar to ours. ${ }^{[2]}$ The success rates of percutaneous and surgical drainage are similar (50-100\% and 65-100\%). ${ }^{[3,10,21]}$ Several studies have shown non-inferior clinical success of endoscopic versus surgical pseudocyst drainage; however, endoscopic drainage was associated with shorter hospital stays, better physical and mental health of patients, and lower cost than surgery. ${ }^{[22,23]}$ Clinical success of endoscopic necrosectomy of WON was around $90 \%$ in another study. ${ }^{[2]}$ Certain factors could be responsible for the results of our study. First, we focused mainly on the efficacy of the therapeutic procedures but did not review other aspects such as length of stay, time to step up the diet, quality of life, and cost-effectiveness. Second, because our study was a retrospective analysis, baseline characteristics in each therapeutic modality had some differences among themselves that could influence the outcome. Third, the high success rate with supportive treatment can be explained by the fact that such patients had mild clinical presentations and complications that could be treated adequately $(40.0 \%$ had abdominal pain that was managed with pain control and $33.3 \%$ had local infections that responded well to antibiotics).

This study shows that the natural history of pseudocyst and WON in current times is largely the same as that in the past except for a few differences. First, although alcohol is still the most common cause of pancreatitis resulting in pseudocyst and WON, its proportion has decreased. This is because it has been replaced by postprocedural pancreatitis from the rising use of endoscopic procedures. Second, peripancreatic collections associated with pancreatic neoplasms have become more obvious in current times, which was not reported in previous studies. This is due possibly to the fact that more advanced diagnostic facilities are available in this modern age. The strong point of our study was that the data of both pseudocyst and WON was collected simultaneously, hence enabling comparison of their natural history, complications, and treatment outcomes. We learned that patients with WON were more symptomatic, had poorer outcomes, and required more aggressive treatment. There were certain limitations to this study. First, the sample size was small. Second, KCMH is a tertiary care hospital and a center of excellence for gastrointestinal disease. Therefore, a selection bias developed when a greater number of patients requiring endoscopic drainage were being referred to this hospital.

In conclusion, over the last four years, post procedure and pancreatic tumor related walled-off PFCs were increasingly found whereas alcohol was still the most common cause. This may reflect a change of practice in terms of treatment and diagnostic evaluation in the current era. The frequency of WON was slightly lower than that reported by several previous reports and may be attributed to improvement in the management of pancreatitis. There has been a paradigm shift toward endoscopic drainage of WPFC. Although clinical success rates of both the endoscopic and surgical drainage are high compared to that of the percutaneous route, the latter technique was performed in more complex cases and seemed to be useful only in cases that were unsuitable for endoscopic drainage.

\section{Conflict of Interest}

There is no conflict of interest.

\section{Source of Foundation}

This study was supported by endowment grant from the Pancreas Research Unit, Faculty of Medicine, Chulalongkorn University, Bangkok, Thailand.

\section{REFERENCES}

1. Banks PA, Bollen TL, Dervenis C, Gooszen HG, Johnson CD, Sarr $\mathrm{MG}$, et al. Classification of acute pancreatitis-2012: revision of the Atlanta classification and definitions by international consensus. Gut 2013; 62:102-11.

2. Wade JW. Twenty-five year experience with pancreatic pseudocysts. Are we making progress? Am J Surg 1985; 149:705-8.

3. Kim KO, Kim TN. Acute pancreatic pseudocyst: Incidence, risk factors, and clinical outcomes. Pancreas 2012; 41:577-81.

4. Cui ML, Kim KH, Kim HG, Han J, Kim H, Cho KB, et al. Incidence, risk factors and clinical course of pancreatic fluid collections in acute pancreatitis. Dig Dis Sci 2014; 59:1055-62.

5. Walt AJ, Bouwman DL, Weaver DW, Sachs RJ. The Impact of Technology on the Management of Pancreatic Pseudocyst: Fifth Annual Samuel Jason Mixter Lecture. Arch Surg 1990;125:759-63.

6. Imrie CW, Buist LJ, Shearer MG. Importance of cause in the outcome of pancreatic pseudocysts. Am J Surg 1988;156:159-62.

7. Vitas GJ, Sarr MG. Selected management of pancreatic pseudocysts: operative versus expectant management. Surgery 1992;111:123-30. 
8. Habashi S, Draganov PV. Pancreatic pseudocyst. World J Gastroenterol 2009; 15:38-47.

9. Cheruvu CV, Clarke MG, Prentice M, Eyre-Brook IA. Conservative treatment as an option in the management of pancreatic pseudocyst. Ann R Coll Surg Engl 2003; 85:313-6.

10. Adams DB, Anderson MC. Percutaneous catheter drainage compared with internal drainage in the management of pancreatic pseudocyst. Ann of Surg 1992;215:571-6.

11. Bapaye A, Itoi T, Kongkam P, Dubale N, Mukai S. New fully covered large-bore wide-flare removable metal stent for drainage of pancreatic fluid collections: Results of a multicenter study. Dig Endosc 2015;27:499504.

12. Ang TL, Kongkam P, Eu Kwek AB, Orkoonsawat P, Rerknimitr R, Fock KM. A two-center comparative study of plastic and lumen-apposing large diameter self-expandable metallic stents in endoscopic ultrasoundguided drainage of pancreatic fluid collections. Endosc Ultrasound 2016;5:320-327.

13. Guo J, Saftoiu A, Vilmann P, Fusaroli P, Giovannini M, Mishra G, et al. A multi-institutional consensus on how to perform endoscopic ultrasound-guided peri-pancreatic fluid collection drainage and endoscopic necrosectomy. Endosc Ultrasound 2017;6:285-91.

14. Bradley EL, Gonzalez AC, Clements JL Jr. Acute pancreatic pseudocysts: incidence and implications. Ann Surg 1976;184:734-7.

15. Maringhini A, Uomo G, Patti R, Rabitti P, Termini A, Cavallera A, et al. Pseudocysts in acute nonalcoholic pancreatitis: Incidence and natural history. Dig Dis Sci 1999; 44:1669-73.

16. London NJ, Neoptolemos JP, Lavelle J, Bailey I, James D. Serial computed tomography scanning in acute pancreatitis: a prospective study. Gut 1989;30:397-403.

17. Barthet M, Bugallo M, Moreira LS, Bastid C, Sastre B, Sahel J. Management of cysts and pseudocysts complicating chronic pancreatitis. A retrospective study of 143 patients. Gastroenterol Clin Biol 1993;17:270-6.
18. Ramia JM, de la Plaza R, Quiñones-Sampedro JE, Ramiro C, Veguillas P, García-Parreño J. Walled-off pancreatic necrosis. Neth J Med 2012;70:168-71.

19. Lowes JR, Rode J, Lees WR, Russell RCG, Cotton PB. Obstructive pancreatitis: Unusual causes of chronic pancreatitis. Br J Surg 1988;75:112933.

20. Papachristou GI, Takahashi N, Chahal P, Sarr MG, Baron TH. Peroral endoscopic drainage/debridement of walled-off pancreatic necrosis. Ann Surg 2007;245:943-51.

21. Lerch MM, Stier A, Wahnschaffe U, Mayerle J. Pancreatic pseudocysts: observation, endoscopic drainage, or resection? Dtsch Arztebl Int 2009;106:614-21.

22. Varadarajulu S, Bang JY, Sutton BS, Trevino JM, Christein JD, Wilcox CM. Equal efficacy of endoscopic and surgical cystogastrostomy for pancreatic pseudocyst drainage in a randomized trial. Gastroenterology 2013; 145:583-90.

23. Saul A, Ramirez Luna MA, Chan C, Uscanga L, Valdovinos Andraca F, Hernandez Calleros J, et al. EUS-guided drainage of pancreatic pseudocysts offers similar success and complications compared to surgical treatment but with a lower cost. Surg Endosc 2016;30:1459-65.

24. Law ST, De La SernaHiguera C, Simón PG, Pérez-MirandaCastillo M. Comparison of clinical efficacies and safeties of lumen-apposing metal stent and conventional-type metal stent-assisted EUS-guided pancreatic wall-off necrosis drainage: a real-life experience in a tertiary hospital. Surg Endosc 2018;32:2448-53.

How to cite this article: Theerasuwipakorn N, Tasneem AA, Kongkam P, Angsuwatcharakon P, Ridtitid W, Navicharern P, et al. Walled-off peripancreatic fluid collections in Asian population: Paradigm shift from surgical and percutaneous to endoscopic drainage. J Transl Int Med 2019; $7: 170-7$ 